1 Faculdade de Medicina de Marília (Famema), Programa de Residência Integrada Multiprofissional em Saúde Coletiva - Marília (SP), Brasil.

marcellabellini@hotmail.com

2 Faculdade de Medicina de Marília (Famema), Residência Integrada Multiprofissional em Saúde Coletiva - Marília (SP),

Brasil. Universidade Estadual Paulista Júlio de Mesquita Filho (Unesp), Faculdade de Medicina, Programa de Pós-Graduação em Saúde Coletiva - Botucatu (SP), Brasil.

danimassihpio@hotmail.com

3 Faculdade de Medicina de Marília (Famema),

Residência Integrada

Multiprofissional em Saúde

Coletiva e Programa de

Desenvolvimento Docente

(PDD) - Marília (SP),

Brasil.

mara@famema.br

\section{O apoiador institucional da Atenção Básica: a experiência em um município do interior paulista}

\author{
The institutional supporter of Primary Care: an experience in a \\ county of the countryside of São Paulo
}

Marcella Bellini', Danielle Abdel Massih Pio $\mathbf{2}$, Mara Quaglio Chirelli3

\begin{abstract}
RESUMO Trata-se de pesquisa qualitativa, realizada com sete apoiadoras institucionais de um município do interior paulista, com o objetivo de verificar o processo experiencial na gestão da Atenção Básica. A partir da análise de conteúdo temática, foi discutida a construção da experiência, da identidade e a necessidade da supervisão-apoio do apoiador institucional. Consideram-se as barreiras na construção de novas práticas de atenção à saúde e de gestão, com o desafio de institucionalizar a proposta e fortalecer a Educação Permanente, como ferramentas para a reorganização da gestão da Atenção Básica.
\end{abstract}

PALAVRAS-CHAVE Atenção Primária à Saúde; Administração de serviços de saúde; Gestão em saúde.

ABSTRACT This is a qualitative research, conducted with seven institutional supporters of a county in the countryside of São Paulo, aiming to verify the experimental process in the management of Primary Care. From the thematic content analysis, it was discussed the construction of experience, identity and the necessity of supervision-support of the institutional supporter. Barriers in the development of new primary care and management practices are considered, with the challenge of institutionalizing the proposition and strengthen Permanent Education, as instruments for the reorganization of Primary Care management.

KEYWORDS Primary Health Care; Health services administration; Health management. 


\section{Introdução}

Tendo em vista que a saúde é um processo construído social e historicamente por indivíduos e coletivos, o olhar lançado para as necessidades e especificidades do trabalho em saúde produz uma nova agenda de gestão. Assim, cada vez mais se faz necessário reorganizar o processo de trabalho para ampliar a escuta e a responsabilização, produzir em equipe e ampliar ferramentas dos trabalhadores para diversificar ofertas a partir das necessidades identificadas.

Com a oferta de tecnologias e dispositivos para a configuração e o fortalecimento desse novo processo de produção do trabalho em saúde, torna-se de extrema importância o apoio a essas equipes, uma vez que não se configura como uma prática puramente técnica, mas, também, relacional. Além de servir como um dispositivo que provoca estranhamentos, ruídos, tensões, conflitos, criação e invenção, também fornece potência ao enfrentamento de problemas cotidianos, acionando tecnologias em vários campos (FRANCO, 2006).

O que se põe em pauta é a ideia de investir também em mudanças na estrutura gerencial e assistencial dos serviços de saúde, criando-se novos arranjos que produzam outra cultura e outras linhas de subjetivação, que não aquelas centradas, principalmente, no corporativismo e na alienação do profissional com o resultado de seu trabalho (CAMPOS, 1998).

É nesse contexto, de acordo com Oliveira (2011), na intercessão das forças e tecnologias produzidas pelos movimentos da saúde coletiva, do Sistema Único de Saúde (SUS), e de democratização institucional, que se insere a proposta de uma metodologia de apoio institucional e suas modalidades de intervenção, ou, como é simplesmente denominado neste trabalho: apoio.

De acordo com a Política Nacional de Humanização (PNH) (BRASIL, 2008), o apoio institucional é um dispositivo de intervenção que propõe um 'modo de fazer' mudanças necessárias para que o SUS se afirme como política efetivamente pública. Com a função 'apoio', procura-se solidificar os princípios do SUS em modos de operar nas unidades de saúde da Atenção Básica $(\mathrm{AB})$, estando junto com os diferentes sujeitos que constituem o sistema de saúde - gestores, usuários e trabalhadores -, articulando as ações dos serviços que compõem a rede, favorecendo trocas solidárias e comprometidas com a dupla tarefa de produção de saúde e produção de sujeitos (GUEDES; ROZA; BARROS, 2012).

O apoio institucional articula trabalhadores e serviço a fim de possibilitar permanente análise crítica sobre o processo de trabalho, bem como a constante renovação de pactos (entre trabalhadores de uma equipe e entre diferentes equipamentos de saúde) para assegurar o cuidado e a ampliação/renovação das tecnologias envolvidas na atenção (MERHY ET AL., 2003).

Referindo-se à função de apoiador, Campos (2006), em seu Método da Roda, define-a como: 1) Um modo complementar para realizar coordenação, planejamento, supervisão e avaliação do trabalho em equipe; 2) Um recurso que procura intervir com os trabalhadores de forma interativa; 3) Uma função que considera que a gestão se exerce entre sujeitos, ainda que com distintos graus de saber e de poder, e que produz efeitos sobre os modos de ser e de proceder desses sujeitos e das organizações; e 4) Depende da instalação de alguma forma de cogestão.

O apoiador institucional, portanto, tem como funções: ativar espaços coletivos que propiciem a interação entre os sujeitos, reconhecendo as relações de poder, afeto e a circulação de saberes; construir objetivos comuns e a viabilização dos projetos pactuados por atores institucionais e sociais; atuar em processos de qualificação das ações institucionais; e promover a ampliação da capacidade crítica dos grupos 
e a transformação das práticas em saúde, contribuindo para melhorar a qualidade da gestão no SUS (OLIVEIRA, 2011).

Por outro lado, como considera Feuerwerker (2014), há a necessidade de uma ampliação da articulação em rede para sustentar sua implementação, bem como a ampliação do coletivo responsável por esse movimento.

Assim, este estudo tem como objeto o apoio institucional da $\mathrm{AB}$ de um município do interior paulista, cuja proposta nasce na respectiva Secretaria Municipal de Saúde (SMS), no início de 2013. Outras denominações de apoio, nessa instituição, foram criadas ao longo da história, coincidindo com a proposta de reorganização do trabalho na lógica da Estratégia Saúde da Família (ESF), o que incluiu o apoio matricial e outra caracterização de apoio institucional anterior, denominada Equipe Gestora da Atenção Básica.

Essa nova configuração da equipe não possui análise e descrição de cargo específicas para sua função, utilizando-se como base o Plano Municipal de Saúde (MARílıA, 2010), elaborado pela SMS do município, e a territorialização como instrumento de organização do processo de trabalho e de ação do apoiador. Ambos trazem como propostas a demarcação de limites das áreas de atuação dos serviços, o reconhecimento do ambiente, da população e da dinâmica social existentes nessas áreas, além do estabelecimento de relações horizontais entre equipes (PEREIRA; BARCELLOS, 2006).

Considerando a territorialização como instrumento de organização e o papel do apoiador nesse processo de produção do cuidado, é relevante observar a implantação desse modelo e a construção dessa prática, que propõe uma lógica dialógica, mas também dialética nos campos constitutivos da implantação da política e da gestão.

Frente às experiências vividas até 0 momento, considera-se que ainda não há clareza da identidade desse papel profissional, com a necessidade de construção desse desenho e de fortalecimento dessa prática, enquanto efetivo arranjo organizacional.

Ademais, diante da recente formalização dessa proposta em âmbito nacional, há ainda poucas publicações e relatos sobre experiências já realizados no País, o que justifica a relevância desta pesquisa.

Desta forma, o presente estudo teve como objetivo verificar o processo experiencial na gestão da $\mathrm{AB}$, tomando como análise a forma como o apoiador significa o seu lugar de trabalho e a sua interpretação acerca do processo de trabalho no qual se vê envolvido, considerando as potências e os desafios para efetivação da lógica da cogestão.

\section{Metodologia}

Este estudo apresenta caráter exploratório-descritivo, com abordagem qualitativa. O cenário é a rede municipal de saúde de um município de médio porte do interior paulista, que conta, atualmente, com 34 unidades de ESF e 12 Unidades Básicas de Saúde (UBS) como atenção primária.

A pesquisa foi realizada com sete funcionárias da rede municipal de saúde, alocadas na SMS, na função de apoiadoras da AB. O critério de inclusão foi terem sido remanejadas para essa função nos anos de 2013 e 2014.

Como instrumento, foi utilizado um roteiro de entrevista semiestruturado, contendo, inicialmente, uma identificação sociolaboral, seguida de uma questão disparadora: 'Conte-me seu processo experiencial quanto à prática de gestão enquanto apoiador institucional da AB'. As entrevistas foram realizadas de forma individual e em locais reservados e agendados previamente na SMS, no período de junho a agosto de 2014, com consentimento das participantes, após aprovação do Comitê de Ética em Pesquisa, sob parecer 
no 638.168. Convém ressaltar que todas as apoiadoras autorizaram sua participação no estudo, permitindo-nos contemplar de forma mais fidedigna a percepção de todas as profissionais incluídas na função.

O referencial metodológico utilizado foi a 'Análise de conteúdo' temática (BARDIN, 2004). Os depoimentos foram analisados individualmente, extraindo as unidades de significado que emergiram da própria descrição com base nos objetivos do estudo. As participantes da pesquisa foram identificadas pela letra 'A', seguida de um numeral (A1 a A7), para garantir o caráter confidencial e a segurança do anonimato.

Os temas que emergiram das análises das entrevistas foram: 'A construção da experiência: os espaços da micro e da macrogestão', 'O desafio de construir uma identidade profissional', 'Supervisãoapoio: o apoio do apoio institucional'. Buscou-se atingir os significados manifestos e latentes trazidos pelos sujeitos, o que foi possível, também, com o uso do referencial teórico psicanalítico na saúde coletiva (CAMPOS, 2013), bem como com os referenciais dos modelos de atenção à saúde, que privilegiam o enfoque da cogestão e das Redes de Atenção à Saúde (RAS) (CAMPOS; DOMITTI, 2007; MENDES, 2010).

Os resultados são apresentados e discutidos a seguir, dispostos com a identificação sociolaboral das entrevistadas e as categorias temáticas analisadas, sob a luz do referencial teórico proposto.

\section{Resultados e discussão}

\section{Identificação sociolaboral}

A partir da análise da identificação sociolaboral, pode-se observar que o apoio institucional da $\mathrm{AB}$ no município conta somente com apoiadoras do sexo feminino e que a média de idade é de 39,6 anos, tendo a apoiadora mais nova 28 anos de idade e a mais velha 56 anos de idade, na data da entrevista.

Do total de apoiadoras, quatro são enfermeiras por formação, representando $57,14 \%$ do total, e três são dentistas/cirurgiã-dentista, o que representa $42,82 \%$ do total. No que se refere à Pós-Graduação, do total de sete apoiadoras, apenas uma não tem especialização na área; seis têm especialização em Saúde da Família; destas, três estão realizando ou já realizaram o mestrado, e uma tem especialização em Gestão em Saúde.

Quanto ao tempo na função, a apoiadora convidada mais recentemente está há dois meses na função. Em contrapartida, a apoiadora que relata estar há mais tempo nessa função é a apoiadora A5 (10 anos); tal fato acontece porque, segundo ela, desde que foi convidada para estar na gestão na SMS, considera exercer o papel de apoiadora das unidades de saúde. Apesar de ser recente a função de apoiadoras da $\mathrm{AB}$, todas já atuavam na $\mathrm{AB}$, tendo histórico de muitos anos na rede municipal de saúde.

\section{Categorias temáticas}

\section{A CONSTRUC̣ÃO DA EXPERIÊNCIA: OS ESPAC̣OS DA MICRO E DA MACROGESTÃO}

$\mathrm{O}$ enfoque do território na $\mathrm{AB}$, para Dias et al. (2009) e Pessoa et al. (2011), permite delinear e caracterizar a população e seus problemas de saúde, a criação de vínculo e responsabilidade entre os serviços de saúde e usuários, propiciando o acesso dos usuários-trabalhadores ao serviço, bem como a avaliação dos impactos das ações.

Neste sentido, busca-se desenvolver práticas de gerência de serviço e assistência à população de cunho participativo, por meio do trabalho em equipe, responsabilizando-se pela assistência em territórios delimitados (denominados microrregiões). Como aponta a apoiadora A2, é necessário 
reconhecer o território para que o planejamento das ações seja produtivo, destacando que:

[...] as equipes realmente precisam conhecer a realidade da sua população para poder fazer sentido as ações que se propõem [...]; a ideia é conhecer mesmo os indicadores de saúde para poder trabalhar, porque cada equipe, mesmo sendo da mesma zona, norte ou sul, são muito diferentes, porque a população tem uma característica muito especifica, e, aí, a equipe também [...].

Para Feuerwerker (2014), é esse território que acaba definindo o modelo de cuidado que vai se conformar na produção de cuidado, pois é nele que operam ao menos duas grandes dimensões a serem destacadas e compreendidas: uma dimensão é a do trabalho morto, que atua a partir dos saberes tecnológicos, que operam como lugares estruturados a priori, visando a governar o trabalho vivo em ato no momento dos processos de construção do cuidado; a outra é a que se refere ao próprio trabalho vivo em ato, no encontro com o outro, e que existe somente neste momento, no ato, sem o qual deixa de existir.

No âmbito da micropolítica, as apoiadoras entrevistadas apontam as diferenças sentidas entre os processos de gestão do micro para o macro. Entre elas, citam:

[...] quando eu vim para cá, aí que eu fui estudar um pouco para ver o que era esse apoio, mas com pouquíssima aproximação teórica, e muito menor ainda prática. Estou aprendendo no dia a dia [...]. (A1).

[...] então, a gente tem que ter esse olhar enquanto gestão, que, na unidade, a gente cuidava ali da micropolítica, e, aqui, a gente tem que ver o macro [...]. (A6).

[...] amplia muito o olhar da gente [...] a gente consegue ter uma visão do todo, que é muito maior que o todo que a gente conhecia [...]. (A3).

Guedes, Roza e Barros (2012) apresentam o apoio institucional como uma estratégia de fomento à gestão compartilhada dos processos de trabalho, exercida nas práticas cotidianas concretas e que parte da premissa de que todo trabalhador é gestor de seu trabalho. É a cogestão tomada como método, colocando o apoiador ao lado dos sujeitos na análise de seus processos de trabalho.

Segundo o Plano Municipal de Saúde 2010-2013 (2010), é função do apoiador criar espaços conjuntos de discussão entre as unidades de saúde de cada região para discutir as competências de cada um e suas formas de articulação, bem como delas com o nível central, minimizando, assim, os conflitos. Nessa perspectiva, o apoiador institucional deve incluir-se ativamente no processo de elaboração de novos modos de produção do cuidado, deslocando-se do papel burocrático e sendo parte das equipes que apoia, proporcionando aos profissionais a ampliação da capacidade de análise e reflexão acerca das dificuldades e possibilidades no cotidiano.

Todavia, devido à fragilidade desse cargo, ainda novo dentro da SMS local, sem atribuições definidas e planejamento de ações traçado, verificam-se nos relatos os desafios encontrados pelas apoiadoras institucionais no dia a dia:

[...] o objetivo do apoiador é provocar mudança no processo de trabalho e no processo de gestão local e dar esse suporte, fazer a ligação da gestão municipal com a gestão local, que é o foco do apoiador, só que é muito difícil você fazer isso, [...] porque você precisa [...] provocar [...] nas equipes, estimular, mas, ao mesmo tempo, animar para o trabalho com o que você tem, ativar a criatividade [...]. (A7).

[...] a gente tem uma grande carga de trabalho burocrática que, em grande parte, talvez essa não seria uma função do apoiador, [...] mas que, 
se a gente vai pegar o conceito do apoio, não seria, e que acaba sendo atribuída, [...] então, isso dificulta o nosso acesso, a estar mais próximo das equipes $[\ldots]$. (A3).

Refletindo sobre as empreitadas diante da necessidade de produzir novas tecnologias de cuidado, Feuerwerker (2014) aponta que há desafios como: construir outro equilíbrio entre os diferentes tipos de tecnologias envolvidos no trabalho em saúde; constituir equipe com um trabalho efetivamente orientado e mobilizado pelas necessidades de saúde não somente do usuário, mas do coletivo familiar em questão; superar a fragmentação do sistema de saúde e produzir continuidade de atenção no interior de uma linha de cuidado, que é produzida em ato para cada situação.

Parte-se, portanto, de um processo em que a mudança é dependente de múltiplos vetores, inseparáveis na produção da saúde: sujeitos, processos de trabalho, poder e políticas públicas (GUEDES; ROZA; BARROS, 2012), cabendo, também, nesse sentido, ao apoiador olhar para as formas de organização do trabalho desde a sua macrogestão.

\section{O DESAFIO DE CONSTRUIR UMA IDENTIDADE PROFISSIONAL}

De acordo com o documento-base da PNH, o apoio institucional é uma diretriz e um dispositivo para ampliar a capacidade de reflexão, de entendimento e de análise de coletivos, a fim de produzir mais e melhor saúde (BRASIL, 2008).

Valorizando os diferentes saberes existentes nos grupos de atuação, o apoiador precisa escutar os trabalhadores e implicá-los nas mudanças de que o SUS necessita; segundo Campos (2013, P. 69), é por esse motivo que se faz necessário

desenvolver não somente dispositivos, mas também arranjos que estimulem a produção de autonomia, criatividade e desalienação de maneira permanente, e complementa, colocando que esses espaços abertos devem ser permanentemente recheados de sentido, nos quais, preferencialmente, um apoio institucional pode ser desenvolvido no papel de suporte (holding) do grupo, tendo como compromisso a produção de saúde ou a clínica ampliada.

De acordo com Ferreira (2008), em um segundo plano organizacional, ocorre o encontro entre os diversos agentes institucionais portadores de diferentes projetos e interesses, que se relacionam, disputam e produzem contratualidades conforme as relações de micropoderes e os tipos de poder presentes nas estruturas dessas organizações, como o político, o técnico e o administrativo. As relações de poder estabelecidas e a relativa autonomia/autogoverno dos trabalhadores na condução do seu processo produtivo definirão o modo de realização da assistência e de articulação dos arranjos tecnológicos.

Nesse sentido, as apoiadoras institucionais vivem em um território ainda em construção e em conquista de um espaço político, técnico e administrativo dentro da secretaria de saúde:

[...] esse papel dos apoiadores [...], essa função foi muito rejeitada, então, até hoje, a gente tem muita dificuldade de trabalhar, atédefalarsobreoqueque é o apoiador, ou muito mais ainda de propor qualquer coisa diferente do que vinha tendo [...]. (A1).

[...] esse desconhecimento de como trabalhar, de como organizar melhor para [...] ter um resultado melhor de cada setor, eu acho que é desconhecido não só pelo apoio, que é uma função nova, mas por vários outros departamentos que já são consolidados [...]. (A2).

As apoiadoras mais recentes relatam suas impressões da função apoiador enquanto estavam nas unidades de saúde, e o discurso revela a distância entre o imaginário e a realidade do processo de trabalho. Como se verifica no relato a seguir, pode-se inferir que esse discurso mostra que ainda não está 
estabelecida a definição do cargo de forma institucional, elaborada de acordo com a PNH:

[...] naquele momento, eu sentia que era uma válvula de escape, uma coisa assim: 'vou passar o problema [...], não estou tendo governabilidade para resolvê-lo. Vamos passar para um órgão maior', que, no caso, seria o apoiador [...]. Eu imaginava que o trabalho fosse bem mais leve. Agora, o tanto que eu estou vendo que é muita burocracia. São muitos detalhes que a saúde pública tem, que o serviço público tem [...]. (A4).

Esse trecho permite uma discussão acerca das novas práticas de processo de trabalho a serem conquistadas nos espaços político, técnico e administrativo dentro da SMS, e que encontram também resistência na burocracia do setor público. No processo de implementação da função apoiador, o processo de trabalho requer novos arranjos da gestão institucional. A esse respeito, Campos (2007) destaca que a proposta é articular os saberes e interesses dos trabalhadores e usuários aos objetivos institucionais. $\mathrm{O}$ apoio implica uma força externa, que está apoiando e sustentando o outro. O Método Paidéia propõe um esforço para construir um novo pensar e agir.

A novidade estaria por conta de integrar estas três dimensões: a liberdade, ou a cidadania, ou a saúde, tudo depende da capacidade de lidar com afetos, com saberes e com o poder. (CAMPOS, 2007, P. 91).

Esse método ainda tem como intenção envolver a política, a gestão, a pedagogia, a clínica e a saúde pública com a lógica da tríplice determinação, ora uma dimensão predomina sobre a outra, sendo que no agir político o poder é o tema predominante. As condições de trabalho, por sua vez, passam por questões relacionadas aos vínculos trabalhistas, até a degradação dos ambientes e processos em sua dimensão cotidiana (SANTOS FILHO; BARROS; GOMES, 2009). Na rotina do trabalho, apontam que as reações perceptíveis em meio a essas condições aparecem como imobilização dos trabalhadores, permeadas por descrença, apatia, raiva, sofrimento patogênico, dor, desprazer, adoecimento. A situação é ilustrada por A7:

[...] e aí como que você vai querer que lá na ponta, né, o profissional que está lá consiga pensar e agir em integralidade? Se o restante do sistema é totalmente desintegrado, é complicado, e isso é um desafio. E é esse o papel do apoiador, e por isso que é um pouco frustrante, porque como que você vai estimular uma equipe a vivenciar, a enraizar, a internalizar a integralidade? [...]. (A7).

Bertussi (2010) destaca que o agir em saúde, em sua micropolítica, traz à cena, permanentemente, as tensões autonomia versus controle num território de disputa e produção incessantes. A vida produtiva se organiza pelas conexões realizadas entre as pessoas e se formam em linhas de fluxos horizontais por dentro das organizações, reveladas pelo discurso:

[...] então, assim, a gente teve um momento de muita tensão, que era um momento de ser reconhecido enquanto apoiador [...], na rede básica em si, e o movimento de ser reconhecido aqui dentro [...]. (A3).

Com base em Bertussi (2010), é possível identificar ferramentas necessárias à 'função', de forma que o apoiador se torne: a) Articulador: produzindo conexão, considerando as singularidades de cada qual e a diversidade e a mobilidade dos possíveis encontros entre sujeitos; b) Educador: agindo pedagogicamente, tomando o mundo do trabalho como matéria prima para o aprendizado; c) Escutador/Observador: agindo a partir da observação do cotidiano, dos movimentos da equipe e seu contexto, sempre aberto à escuta; d) Facilitador: facilitando processos que contribuam para colocar as potências dos sujeitos e dos coletivos em evidência; e e) 
Negociador: mediando e buscando compatibilizar os interesses distintos envolvidos na formulação dos acordos e projetos comuns.

Revela-se o processo de mudança de posicionamento da função apoiador frente às relações estabelecidas e definidas na SMS, a partir dos fragmentos:

[...] Hoje, nós estamos em um processo aqui dentro que é de sentar com esses grupos, com essas pessoas, com esses setores e mostrar de onde vem essa função apoiador. Então, começamos a falar um pouquinho da PNH, começamos a falar um pouquinho da Política Nacional da Atenção Básica, começamos a conversar sobre os financiamentos do Ministério da Saúde em relação à Estratégia e à UBS, então, parece que a nossa aceitação está um pouquinho melhor [...]. (A1).

[...] quando eu entrei, já estava existindo um movimento com os grupos temáticos de fazer uma apresentação de qual a função deles, que foi um pedido do secretário [...], então, para mim, foi bom para ter o conhecimento de qual a função de cada um [...]. (A4).

Nesse sentido, como aponta Santos Filho, Barros e Gomes (2009), ao mesmo tempo que se investe na construção gradual do compartilhamento (cogestão), constrói-se um campo fértil de 'comunicação intercompreensão', que traz em si um potencial de ampliação do 'entendimento' do trabalho entre sujeitos.

O desafio se coloca, no entanto, diante do SUS real, que, apesar de todos os avanços, está muito distante da proposta almejada pelo movimento. O modelo assistencial e a organização da gestão são todos elementos críticos desse processo.

\section{Supervisão-apoio: o apoio do apoio institucional}

A fim de fortalecer os sujeitos e os coletivos inseridos na construção de processos de cogestão e democratização das relações de poder, os arranjos de apoio contribuem no sentido de transformar os modelos de gestão hierarquizados em modelos mais horizontalizados.

O apoio, segundo Campos (2007), é pensado como uma função gerencial que, a partir do princípio da cogestão, reformula o modo tradicional de fazer coordenação, planejamento, supervisão e avaliação em saúde. Nesse sentido, novos arranjos políticos, de gestão e de participação, são, portanto, indispensáveis (MERHY, 2003).

De acordo com Campos (2007), para que se realize a 'função' de apoio, são necessários, ao apoiador institucional, alguns recursos metodológicos, entre os quais: (a) capacidade de construir rodas, ou seja, todo apoiador institucional é um ativador de espaços coletivos visando à interação dos sujeitos na análise de situações e na tomada de decisão; (b) habilidade para incluir as relações de poder, de afeto e a circulação de conhecimentos em análise; (c) capacidade de pensar e fazer junto com as pessoas e não em lugar delas, estimulando a capacidade crítica dos sujeitos; (d) habilidade de apoiar o grupo para construir objetos de investimento e compor compromissos e contratos; e (e) capacidade de trabalhar com uma metodologia dialética que, ao mesmo tempo que traga ofertas externas, valorize as demandas do grupo apoiado.

Todavia, esses recursos metodológicos precisam ser refletidos, reelaborados e trabalhados sempre coletivamente. Considera-se, também, que, ao reconhecer as necessidades, a instituição apoie o processo de formação para a instrumentalização com relação às ferramentas pertinentes. As apoiadoras revelam que suas ações ainda são frágeis no âmbito da necessidade do fortalecimento político que embase essa prática e fortaleça essa capacitação técnica:

[...] tinha uma proposta de capacitação que se perdeu com a saída do gestor, com outras demandas que teve aqui na secretaria, e se perdeu essa 
capacitação. Iniciou, porém, não teve continuidade. Então, a gente estava trabalhando conforme a gente imaginava que fosse o ideal [...]. (A1).

[...] Olhando para a atenção municipal, no planejamento municipal, a experiência como apoiador ainda é muito frágil, porque falta ainda uma integração e até mesmo conhecimento dessas ferramentas de planejamento em saúde a nível municipal. Então, é algo que, nesse processo de construção do papel do apoiador, ainda está frágil [...]. (A7).

De acordo com Falleiro (2014), o trabalhador que inicie sua jornada como Apoiador Institucional poderá tomar as ferramentas citadas por Campos (2007) como orientadoras do seu processo de trabalho, no entanto, é fundamental que as apoiadoras institucionais manifestem seu desejo de aprimoramento profissional e informem sua demanda de Educação Permanente (EP), assim como é fundamental que a instituição/órgão capte essa demanda e invista na formação de sua equipe.

Prosseguindo no discurso das apoiadoras, é possível verificar que existia expectativa de que o processo de supervisão-apoio fosse iniciado à medida que suas atribuições nesse novo cargo se iniciassem:

[...] eu achei que eu chegaria e teria um apoio técnico $[. .$.$] , que tivesse um conhecimento, um$ arcabouço teórico bom, que falasse [...], que a gente chegasse com uma dúvida, com um problema, e falasse 'não [...] dá para fazer isso [...], dá para fazer aquilo [...], vamos pensar juntos [...], existe essa portaria, existe aquela', e isso não existiu [...]. (A7).

Como considera Feuerwerker (2014, P. 103),

cuidar de si é pressuposto para cuidar dos outros, dá potência ao trabalhador da saúde para a sua produção cotidiana. E o processo autoanalítico pode criar esse efeito na equipe.
De acordo com a autora, o processo autoanalítico refere-se a, além de 'olhar para si', operar movimentos de desterritorialização e reterritorialização com relação à prática de produção do cuidado, de tal maneira que o processo autoanalítico se realize por meio da Educação Permanente em Saúde (EPS).

Na EPS, o processo de trabalho é tomado como objeto da reflexão participativa e ativa pelos trabalhadores. É a partir da realidade de suas práticas, das concepções que portam e de suas relações de trabalho que se constroem os processos educativos. Nesse sentido, a EPS é uma estratégia fundamental para as transformações do trabalho em saúde, a fim de que ele se torne lugar de crítica reflexiva, propositiva, compromissada e tecnicamente competente (CECCIM, 2005).

Existe um movimento em nível estadual, em parceria com o município, a fim de sistematizar reuniões e grupos de EP com o Departamento da Atenção Básica e outros departamentos da SMS. Pode-se perceber a importância desse momento para as apoiadoras através dos trechos dos discursos de A7 “[...] então, a educação permanente é uma ferramenta potente em qualquer espaço de trabalho, e, para nós, tem sido importantíssimo [...]" e de A6

[...] a gente solicitou e foi concedida a presença do articulador da Atenção Básica da DRS para vir toda semana, e ela faz uma EP com o grupo [...]. Isso ajudou bastante o grupo até saber o que que é o apoio institucional, qual que é o papel do apoiador. Isso está em construção ainda para este grupo. A gente fez o movimento de listar tudo que a gente faz aqui de tudo [...], depois tentar separar, então debruçar no que a política fala do apoiador, debruçar naquilo e separar de fato o que que é a função do apoiador e o que não, e daí a gente conseguiu ver, visualizar que muita coisa que a gente faz não é do apoiador [...].

Pode-se observar nas falas das apoiadoras o reconhecimento da EPS como instrumento para a formação e o desenvolvimento dos 
trabalhadores da saúde no contexto do SUS. De acordo com Ceccim (2005), a política de EPS coloca em ato uma prática rizomática de encontros e produção de conhecimento.

Todavia, Feuerwerker (2014) considera que há uma ausência evidente nesse processo: 0 usuário. Ausência tal que pode ser percebida também no discurso das apoiadoras no que se refere à prática de EPS. Tal movimento tem sido trabalhado prioritariamente no âmbito da relação gestão-trabalhadores, algumas vezes envolvendo também professores e estudantes, mas, como considera a autora, pouquíssimas vezes usado como estratégia para ampliar os encontros, 'a superfície de contato' e de produção mútua entre trabalhadores e usuários. Tal constatação pode ser considerada um ponto a ser mais bem discutido e aprimorado no processo de EPS, no âmbito da SMS, junto ao Departamento de Atenção Básica.

\section{Considerações finais}

Esta pesquisa incorpora as discussões acerca da micropolítica do trabalho dos apoiadores da $A B$ na SMS de um município do interior paulista. Considerando que o objeto de trabalho do apoiador é o processo de trabalho de coletivos que se organizam para produzir saúde, a função apoio é chave para a instauração de processos de mudança em grupos e organizações, construindo espaços coletivos de cogestão, educação e formação.

Importante sinalizar as barreiras que a equipe de apoiadores institucionais encontrou para a construção de novas práticas de atenção à saúde e à gestão, como a mudança do gestor local em pouco tempo de atuação, reformulação da equipe de apoiadores e falta de suporte (holding) do próprio grupo de apoio.

Há a necessidade da institucionalização dessas práticas sob a forma de planos mais específicos e descritos para a função de apoiador e do fortalecimento da EP para a formação e o desenvolvimento profissional desse trabalhador. Assim, é fundamental que haja interesse pelo aprimoramento profissional através de EP e que, além disso, a instituição/órgão capte essa demanda, invista e reforce a formação de sua equipe. Importante lembrar que os processos de EP favorecem o trabalhador na (re)construção de sua práxis, ressignificando-a e podendo transformá-la em processo. A possibilidade das apoiadoras entrevistadas expressarem sua vivência através de seus relatos também pode ser sentida como um momento em que lhes foram dadas voz e oportunidade de refletir e repensar sua prática e suas necessidades enquanto sujeitos dos processos.

Pode-se considerar que, apesar das tensões constitutivas do campo da gestão, o apoio institucional tem se efetivado como uma forte estratégia no suporte para a reorganização da gestão da $\mathrm{AB}$.

\section{Referências}

\section{BARDIN, L. Análise de conteúdo. 3 ed. Lisboa: Edições 70, 2004.}

BERTUSSI, D. C. O Apoio Matricial Rizomático e a produção de coletivos na Gestão Municipal em Saúde. 2010. 234 f. Tese (Doutorado em Clínica Médica) Universidade Federal do Rio de Janeiro, Rio de Janeiro, 2010.
BRASIL. Ministério da Saúde. Secretaria de Atenção à Saúde. Núcleo Técnico da Política Nacional de Humanização. HumanizaSUS: documento base para gestores e trabalhadores do SUS. 4. ed. Brasília, DF: MS, 2008.

CAMPOS, R. O. Psicanálise \&t Saúde Coletiva: interfaces. São Paulo: Hucited, 2013 
CAMPOS, G. W. S. O anti-Taylor: sobre a invenção de um método para co-governar instituições de saúde produzindo liberdade e compromisso. Cadernos de Saúde Pública, Rio de Janeiro, v. 14, n. 4, p. 863-870, 1998.

Clínica e saúde coletiva compartilhadas: teoria Paidéia e reformulação ampliada do trabalho em saúde. In: CAMPOS, G. W. S. et al. Tratado de Saúde Coletiva. São Paulo: Hucitec, Rio de Janeiro: Fiocruz, 2006. p. 53-92.

CAMPOS, G. W. S.; DOMITTI, A. C. Apoio matricial e equipe de referência: uma metodologia para gestão do trabalho interdisciplinar em saúde. Cadernos de Saúde Pública, Rio de Janeiro, v. 23, n. 2, p. 399-407, 2007.

CECCIM, R. B. Educação Permanente em Saúde: descentralização e disseminação de capacidade pedagógica na saúde. Ciência \& Saúde Coletiva, Rio de Janeiro, v. 10, n. 4, p. 975-986, 2005.

DIAS, E. C. et al. Saúde ambiental e saúde do trabalhador na Atenção Primária à Saúde, no SUS: oportunidades e desafios. Ciência \&t Saúde Coletiva, Rio de Janeiro, v. 14, n. 6, p. 2061-2070, 2009.

FALLEIRO, L. M. (Org.). Experiências de apoio institucional no SUS: da teoria à prática. Porto Alegre: Rede Unida, 2014. (Micropolítica do Trabalho e o Cuidado em Saúde).

FEUERWERKER, L. C. M. (Org.). Micropolítica e saúde: produção do cuidado, gestão e formação. Porto Alegre: Rede Unida, 2014. (Micropolítica do Trabalho e o Cuidado em Saúde).

FERREIRA, V. S. C. Micropolitica do processo de trabalho do Agente Comunitário de Saúde (ACS): território de produção de cuidado e subjetividade. Rio de Janeiro: UFRJ, 2008.

FRANCO, T. B. As redes na micropolítica do processo de trabalho em saúde. In: PINHEIRO, Mattos (Org.). Gestão em Redes. Rio de Janeiro, Cepesc: IMS/Uerj: Abrasco, 2006. p. 459-473.
GUEDES, C. R.; ROZA, M. M. R.; BARROS, M. E. B. O apoio institucional na Política Nacional de Humanização: uma experiência de transformação das práticas de produção de saúde na rede de Atenção Básica. Cad. Saude. Colet., Rio de Janeiro, v. 20, n. 1, p. 93-101, 2012.

MARÍLIA. Secretaria Municipal de Saúde. Plano Municipal de Saúde de Marília - 2010-2013. Marília, 2010.

MENDES, E. V. As redes de atenção à saúde. Ciência \& Saúde Coletiva, Rio de Janeiro, v. 15, n. 5, p. 2297-2305, 2010.

MERHY, E. E. et al. O trabalho em saúde: olhando e experienciando o SUS no cotidiano. São Paulo: Hucitec, 2003.

OLIVEIRA, G. N. Devir apoiador: uma cartografia da função apoio. 2011. 175f. Tese (Doutorado em Saúde Coletiva) - Universidade Estadual de Campinas, São Paulo, 2011.

PEREIRA, M. P. B.; BARCELLOS, C. O território no Programa de Saúde da Família. Hygeia, Revista Brasileira de Geografia Médica e da Saúde, Uberlândia, v. 2 , n. 2 , p. $47-55,2006$.

PESSOA, V. M. et al. As novas necessidades de saúde nos territórios dos sertanejos do baixo Vale do Jaguaribe-CE e os desafios à política pública de saúde. In: RIGOTTO, R. M. (Org.). Agrotóxicos, trabalho e saúde. Fortaleza: UFC, p. 549-583, 2011.

SANTOS FILHO, S. B.; BARROS, M. E. B.; GOMES, R. S. A Política Nacional de Humanização como política que se faz no processo de trabalho em saúde. Interface (Botucatu), Botucatu, v. 13, supl. 1, p. 603-613, 2009.

Recebido para publicação em abril de 2015

Versão final em setembro de 2015

Conflito de interesses: inexistente

Suporte financeiro: não houve 